\title{
DISAIN DAN KARAKTERISTIK JARING PUKAT CINCIN UKURAN SEDANG DI PANTAI UTTARA JAWA
}

\author{
Wijopriono") dan Mahiswara*)
}

\begin{abstract}
ABSTRAK
Perikanan pukat cincin ukuran sedang telah berkembang di utara Jawa. Penelitian mengenai alat tangkap tersebut telah dilakukan pada bulan September - Oktober 1993, dengan tujuan untuk memperoleh data dan informasi mengenai disain dan karakteristiknya bagi pengembangan di daerah perairan lainnya. Penelitian dilaksanakan dengan melakukan pengukuran, pengoperasian dan wawancara. Hasil penelitian menunjukkan bahwa disain pukat cincin kebanyakan adalah tipe Jepang, di mana posisi kantong terdapat di bagian tengah. Bahan jaring terbuat dari nilon benang ganda 210 $\mathrm{d} / 12$ untuk bagian kantong, nilon benang ganda $210 \mathrm{~d} / 9$ dan $210 \mathrm{~d} / 6$ untuk bagian sayap. "Hanging ratio" yang digunakan adalah $0,48-0,63$, sementara perbandingan diameter benang terhadap panjang kaki mata jaring/bar (D/L) adalah $0,31-0,63$. Perbandingan daya apung terhadap daya tenggelam lebih dari 2. Dengan nilai perbandingan seperti ini, kelemahan material nilon yang memiliki nilai berat jenis rendah dapat teratasi, sehingga disain yang ada memungkinkan memiliki kecepatan tenggelam yang optimum. Dilihat dari pola potong jaring, terdapat dua model pukat cincin ukuran sedang, yaitu model selendang dan serong. Model selendang memiliki kelebihan dari aspek perakitan, penanganan dan kekuatan.
\end{abstract}

ABSTRACT : Net Design and Characteristics of The Medium Size Purse Seine in Northern Coast of Java, By: Wijopriono and Mabiswara.

Medium size purse seine have developed in Northern Coast of Java. The study of its gears was conducted from September to October 1993 to know the net design and characteristics for developing in other waters. Analysis was based on data observations through measuring and fishing operation. The result shown that the existing design in this area is Japanese type in which the position of bunt is in the midle part of net. Netting material made of nylon multifilament $210 \mathrm{~d} / 12$ for bunt part of the net, nylon multifilament $210 \mathrm{~d} / 9$ and $210 \mathrm{~d} / 6$ for the wing. Hanging ratio of the net is 0,48 to 0,63 , while ratio of the twine diameter to the length of bar $(D / L)$ is 0,31 to 0,63 . Ratio total bouyancy to total sinking force $(\mathrm{S} / \mathrm{F})$ is more than 2 , to over-come low sinking speed caused by the use of nylon material for webbing which has low specific gravity. Based on the tappering construction, there are two types of medium size purse seine, namely "selendang" and "serong". Selendang type has more advantage in rigging and handling aspects.

KEYWORDS: Net desigm, purse seine, fusbing gear

\section{PENDAHULUAN}

Pukat cincin (purse seine) merupakan alat tangkap yang efektif untuk menangkap ikan pelagis yang memiliki tingkah laku hidup berkelompok dalam ukuran besar, baik di daerah perairan pantai maupun lepas pantai. Pukat cincin adalah alat tangkap berbentuk empat persegi panjang, yang keseluruhan bagian

-) Peneliti pada Balai Penelitian Perikanan Laut, Jakarta 
utamanya terbuat dari bahan jaring, di mana terbentuknya kantong terjadi pada saat dioperasikan. Pengoperasian alat tangkap ini dengan cara melingkarkan dan kemudian ditarik. Dalam operasinya posisi pelampung dan tali ris atas berada di permukaan, sementara pemberat, cincin dan tali ris bawah menggantung di bagian bawah jaring, dan berada di dalam laut. Melalui cincincincin ini terpasang tali kolor (purse line) yang bila ditarik menjadikan bagian bawah jaring menutup, sehingga bentuk jaring secara keseluruhan menyerupai mangkuk besar (Sainsbury, 1971). Rancang bangun dan konstruksi dari pukat cincin secara teknis mempengaruhi kecepatan tenggelam badan jaring, kecepatan melingkarkan jaring serta kecepatan penarikan tali kolor.

Di daerah perairan utara Jawa, perikanan pukat cincin merupakan unit penangkapan yang memberikan konstribusi yang besar terhadap total produksi perikanan. Perikanan pukat cincin di daerah perairan utara Jawa mengalami perkembangan sejak mulai diintroduksikan, sekitar tahun 70-an (Yusuf, 1978). Sampai dengan tahun 1981 daerah penangkapan pukat cincin yang berada di utara Jawa masih berada di sekitar Pulau Karimunjawa dan Pulau Bawean. Namun semenjak tahun tersebut, berkembang meliputi seluruh perairan laut Jawa, bagian selatan Laut Cina Selatan dan Selat Makasar (Nurhakim et al., 1987). Berkembangnya daerah penangkapan pukat cincin ke wilayah perairan yang semakin jauh dari tempat pendaratan menyebabkan trip penangkapan semakin panjang, dimensi kapal semakin besar dan jumlah trip per kapal per tahun menurun (Potier et al., 1990).

Perkembangan tersebut juga berdampak terhadap keseluruhan bentuk perikanan pukat cincin. Perbedaan kemampuan pemilikan modal, perhitungan ekonomis dan teknis serta kondisi basis penangkapan, merupakan sebagian penyebab timbulnya tiga bentuk pukat cincin yaitu perikanan pukat cincin besar (big purse seiners), pukat cincin ukuran sedang (medium size purse seiners) dan pukat cincin mini (mini purse seiners). Potier dan Sadhotomo (1995) menyatakan bahwa, unit penangkapan pukat cincin ukuran sedang, dioperasikan menggunakan kapal kayu dengan panjang (LOA) antara 15-20 m. Tenaga penggerak yang digunakan berkisar antara 35-100 HP. Kapal dilengkapi palka dengan kapasitas muat 20-25 ton ikan segar. Daerah operasinya adalah perairan pantai dan lepas pantai pada kedalaman perairan antara $30-45 \mathrm{~m}$. Jumlah hari operasi dalam satu trip antara 8-15 hari. Pukat cincin besar berkembang khususnya di daerah Tegal, Pekalongan dan Juwana (Pati). Dalam pengoperasiannya pukat cincin besar menggunakan kapal berukuran panjang lebih dari 24,0 meter, dan daerah operasinya mencapai perairan Laut Cina Selatan bagian selatan serta perairan Selat Makasar bagian utara. Jenis alat tangkap pukat cincin mini berkembang khususnya di luar Pekalongan seperti daerah Rembang, Sarang dan Jawa Timur pada umumnya, di mana daerah operasinya hanya di sekitar pantai, dan menggunakan kapal dengan mesin luar (outboard) berporos panjang (pole drive engine). 
Unit penangkapan pukat cincin ukuran sedang hingga saat ini hanya berkembang di wilayah Jawa Tengah. Menilik pada aspek teknisnya, unit penangkapan tipe tersebut masih memungkinkan untuk dikembangkan di wilayah lain, yang minimal memiliki kesamaan karakter dengan daerah perkembangannya saat ini.

Penelitian ini dilakukan khususnya untuk mengetahui karakteristik secara teknis alat tangkap pukat cincin ukuran sedang. Disain, perlengkapan dan material yang digunakan serta karakteristik yang terbentuk merupakan bahan pembahasan dengan maksud agar dapat memberikan gambaran yang jelas tentang alat tangkap tersebut untuk kemungkinan pengembangannya di daerah lain.

\section{BAHAN DAN METODE}

Penelitian dilaksanakan pada bulan September - Oktober 1993, di daerah Pekalongan dan Batang, Jawa Tengah. Kedua daerah ini dianggap cukup mewakili, mengingat bahwa bagian terbesar pukat cincin ukuran sedang yang beroperasi di perairan utara Jawa berada di wilayah ini. Penelitian dilakukan dengan melakukan pengukuran terhadap alat tangkap, pengamatan langsung dalam pengoperasian serta wawancara dengan praktisi di lapangan. Perhitungan beberapa parameter alat tangkap didasarkan atas formula yang dikemukakan oleh Prado dan Dremiere (1991):

\section{Bobot jaring bersimpul:}

$$
W=H \times L \times R \text { tex } / 1000 \times K
$$

$$
\text { di mana } \begin{array}{ll}
\mathrm{W} & =\text { Bobot jaring yang diperkirakan }(\mathrm{g}) \\
\mathrm{H} & =\text { Jumlah baris simpul pada tingi jaring } \\
\mathrm{L} & =\text { Panjang jaring dalam keadaan tegang }(\mathrm{m}) \\
\mathrm{R} t e x & =\text { Ukuran benang jaring } \\
\mathrm{K} & =\text { Faktor koreksi simpul sesuai dengan berat simpulnya }
\end{array}
$$

\section{Daya apung dan tenggelam:}

$$
P=A x(1-D W / D M)
$$

$$
\text { di mana } \begin{array}{ll}
\mathrm{P} & =\text { Bobot di dalam air }(\mathrm{Kg}) \\
\mathrm{A} & =\text { Bobot di udara }(\mathrm{Kg}) \\
\mathrm{DW} & =\text { Densitas air }(\mathrm{g} / \mathrm{cc}) ; \text { untuk air laut } 1,026 \\
\mathrm{DM} & =\text { Densitas bahan }(\mathrm{g} / \mathrm{cc})
\end{array}
$$


Tinggi jaring adalah:

$$
T, x \sqrt{1-E^{2}}
$$

$$
\text { di mana } \begin{aligned}
\mathrm{T}_{j} & =\text { Tinggi tegang jaring }(\mathrm{m}) \\
\mathrm{E}^{2} & =\text { Kuadrat banging ratio mendatar }
\end{aligned}
$$

\section{HASIL. DAN PEMBAHASAN}

\section{Disain Alat Tanghap}

Disain alat tangkap pukat cincin ukuran sedang di Utara Jawa dalam perkembangannya hingga saat ini tidak mengalami banyak perubahan. Perubahan yang menonjol bukan terjadi pada disainnya, tetapi dalam hal dimensi alat tangkap. Secara umum disain dan pola potong pukat cincin ukuran mini, sedang dan besar adalah sama.

Menilik rancang bangun dan konstruksinya saat ini terdapat dua tipe pukat cincin yaitu, tipe Amerika dan tipe Jepang. Perbedaan kedua tipe tersebut terdapat pada posisi terbentuknya kantong. Pukat cincin tipe Amerika, posisi kantong berada di bagian sisi jaring, sedangkan tipe Jepang, letak kantong di bagian tengah (Ayodhyoa, 1981). Pukat cincin ukuran sedang yang ada di perairan utara Jawa adalah tipe Jepang. Penggunaan tipe ini diduga erat kaitannya dengan kemudahan dalam pengoperasian oleh karena kebiasaan nelayan di daerah ini yang mengoperasikan alat tangkap dengan kantong di bagian tengah seperti pada payang dan lampara.

\section{Dimensi dan Pola Potong (taper cat) Jaring}

Pada awal perkembangannya, berdasarkan sampel alat tangkap yang diperoleh, panjang jaring terpasang (panjang pada ris atas) adalah $258,0 \mathrm{~m}$ atau 5 pis jaring yang disambung secara horizontal. Jaring ini dalam istilah setempat disebut "jaring sambung lima" (Figure 1).

Dengan menggunakan rumus perhitungan tinggi jaring (3) diperoleh nilai bagian terpanjang ke arah vertikal atau tinggi jaring (bagian kantong) 93,0 m (11 pis ke bawah). Dimensi alat tangkap pukat cincin ukuran sedang ini dari tahun ke tahun semakin bertambah besar, mengikuti perkembangan ukuran kapal yang digunakan.

Saat ini ukuran panjang terpasang jaring pukat cincin ukuran sedang yang digunakan mencapai $368,0 \mathrm{~m}$ atau 6 pis horizontal. Jaring ini disebut "jaring sambung enam" (Figure 2). Tinggi jaring (bagian kantong) mencapai 110,0 m 


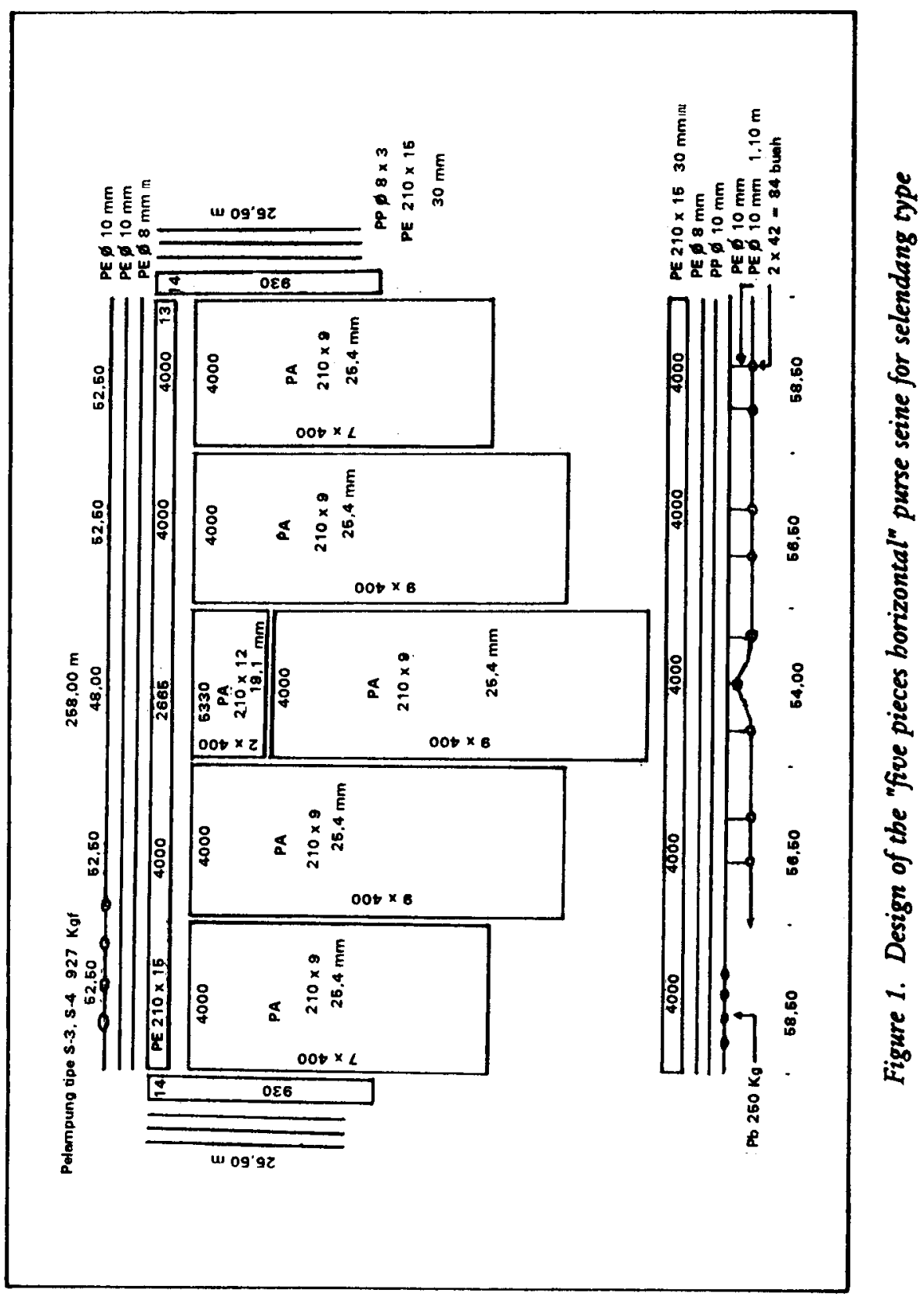




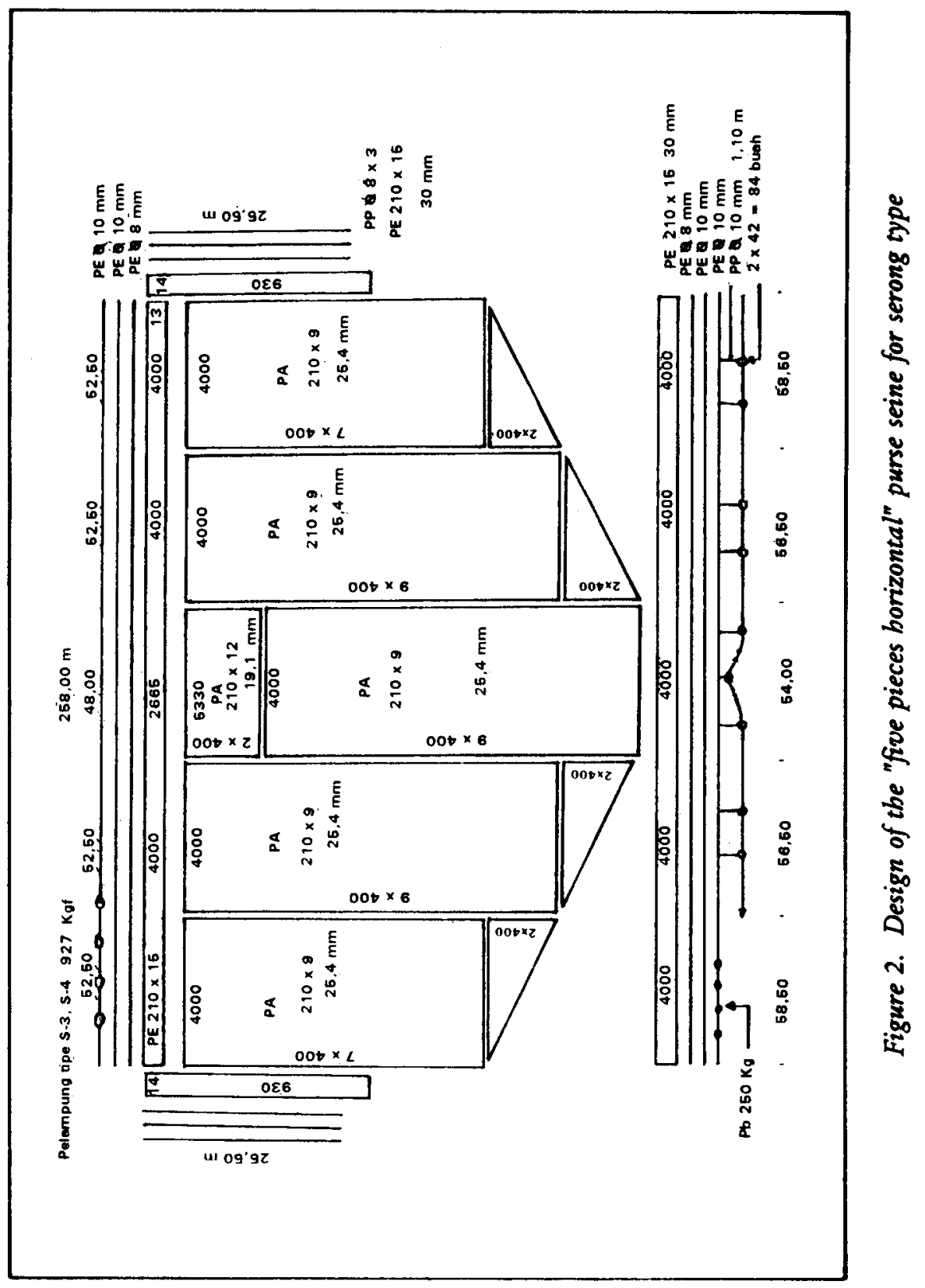


(14 pis ke bawah). Ukuran tinggi jaring pukat cincin ini nampaknya berlebihan apabila melihat kedalaman daerah pengoperasiannya. Namun keadaan ini dapat dipahami oleh karena beberapa hal berikut:

a. Tinggi jaring yang mencapai dasar/dekat dasar perairan diarahkan untuk memperkecil kesempatan ikan meloloskan diri secara vertikal.

b. Pengoperasian pukat cincin mengharapkan penampilan jaring di dalam air yang menggelembung di bagian tengah jaring agar memperoleh area cakupan yang luas. Dengan performansi demikian bukaan mata tidak teregang maksimal sehingga memperkecil ikan terjerat.

c. Ukuran tinggi jaring yang besar menjadikan penarikan (oleh tenaga manusia) sebelum ikan terkumpul di bagian kantong relatif lebih ringan, oleh karena ikan hasil tangkapan tetap berada pada kolom air.

Pemotongan jaring pada pis bagian bawah dengan bentuk bentuk serongan (tapering) dari bagian tengah (bawah kantong) sampai sayap bagian ujung terdapat dua model. Pertama adalah model "serong", di mana pis jaring bagian bawah dipotong miring (bar-point). Bentuk ini oleh Prado dan Dremiere (1991) disebut pukat cincin model lampara. Tipe ini banyak dijumpai pada awal perkembangan pukat cincin, dan sampai sekarang beberapa unit pukat cincin masih menggunakannya, terutama yang berada di daerah Batang, Jawa Tengah (Figure 3). Jaring model ini memiliki performansi yang baik bila dioperasikan di perairan yang dalam dan arusnya cukup kuat, di mana bagian bawah jaring tidak sampai menyentuh dasar perairan. Namun bila dioperasikan di perairan dangkal, jaring bagian bawah akan cepat rusak. Di samping itu, perakitan jaring akan membutuhkan waktu yang lama.

Kedua adalah model "selendang", di mana dalam membentuk serongan (tapering) jaring dikerut tanpa dipotong miring/diagonal (Figure 4). Bentuk ini oleh Prado dan Dremiere (1991) disebut pukat cincin tipe ring net. Sejauh ini belum diperoleh data mengenai penggunaan model disain pukat cincin, namun terdapat kecenderungan bahwa model selendang lebih berkembang di pantai utara Jawa. Hal ini diduga karena disamping pengerjaan perakitan jaring lebih mudah, juga dianggap tidak mudah rusak dibandingkan dengan model serong.

\section{Panjang Terpasang (Hanging ratio)}

Hanging ratio (panjang jaring terpasang) untuk bagian-bagian jaring " 5 pis horizontal" (sambung lima) adalah $\mathrm{E}=0,48$ untuk bagian kantong, $\mathrm{E}=0,52$ bagian sayap tengah dan ujung. Sedangkan hanging ratio untuk bagian-bagian jaring "enam pis horisontal" (sambung enam) adalah 0,58 untuk bagian kantong, $E=0,62$ bagian sayap tengah dan $E=0,63$ untuk bagian ujung sayap. Di sini nampak bahwa, bertambahnya ukuran panjang jaring merubah nilai hanging ratio pada bagian-bagian jaring menjadi sedikit lebih besar. 


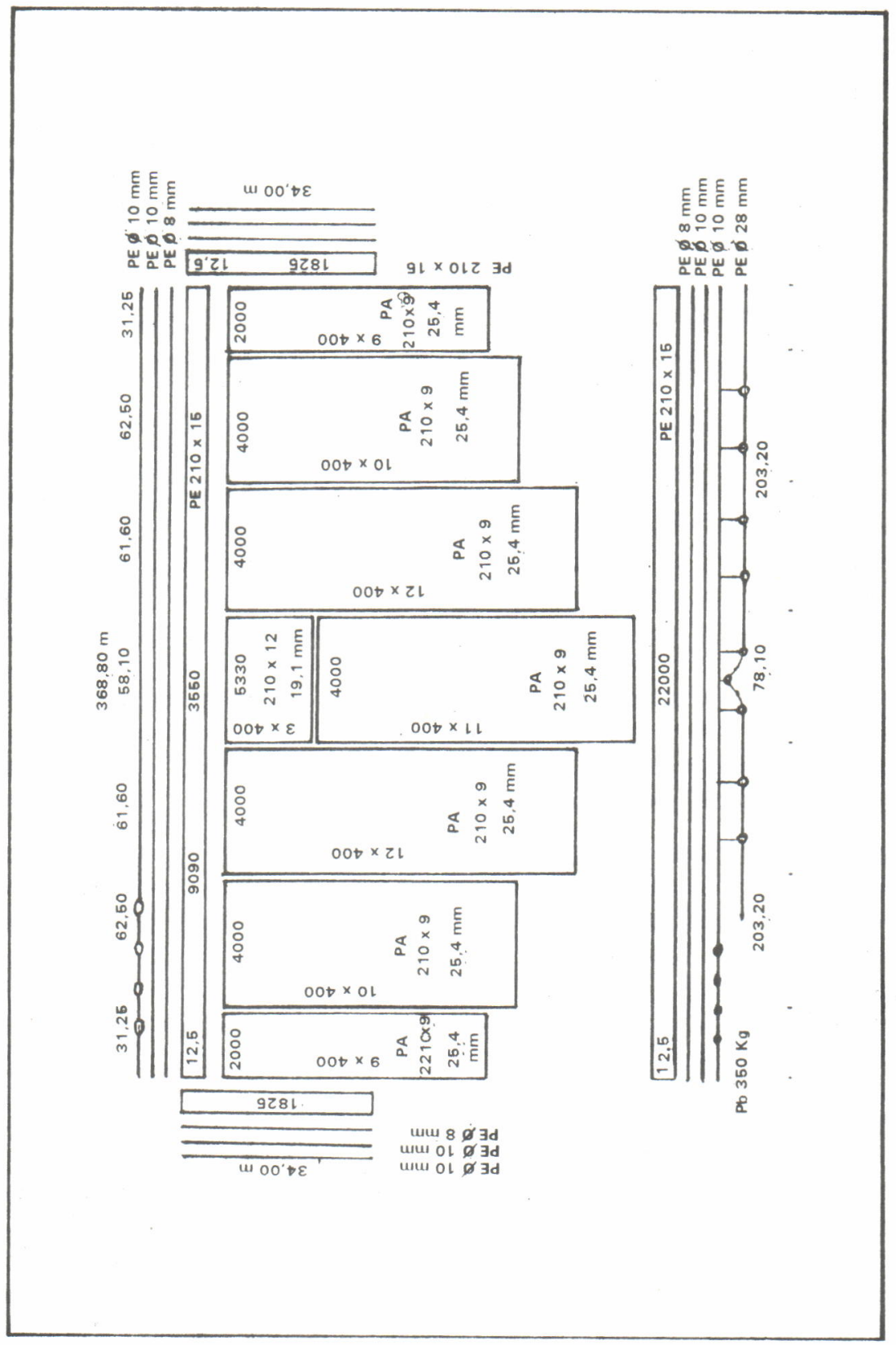

है 


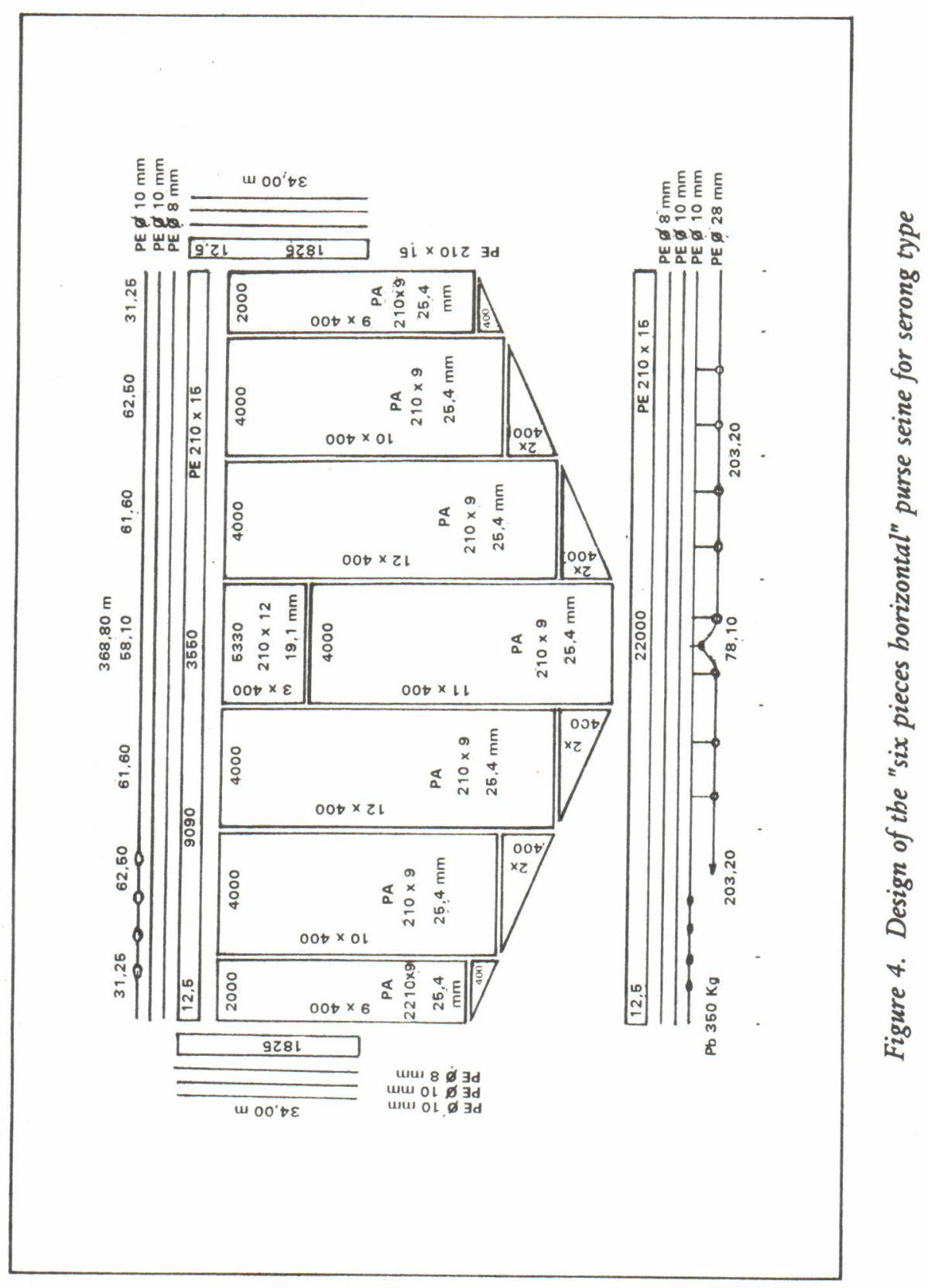


Nilai hanging ratio dengan bukaan mata jaring terbesar adalah $\mathrm{E}=0,71$, sehingga semua nilai hanging ratio yang mendekati ke arah nilai tersebut, bukaan mata jaringnya akan semakin besar. Semakin besar bukaan mata jaring, maka akan semakin kecil resistensinya dalam air.

Nilai banging ratio yang diberikan pada pukat cincin ukuran sedang tipe sambung lima dan enam berkisar antara $0,48-0,63$, untuk keseluruhan bagian. Dengan nilai tersebut dapat diharapkan kecilnya resistensi, sehingga mampu meningkatkan kecepatan tenggelam pukat cincin saat dioperasikan.

\section{Bahan}

Bahan jaring yang digunakan pada pukat cincin ukuran sedang adalah nilon benang ganda (nylon multifilament) dengan nomor benang $210 \mathrm{~d} / 12$ untuk bagian kantong, dan $210 \mathrm{~d} / 9$ untuk bagian sayap serta bagian di bawah kantong. Namun demikian terdapat pula yang menggunakan benang $210 \mathrm{~d} / 9$ dan $210 \mathrm{~d} / 6$ pada bagian sayap serta di bawah kantong. Benang $210 \mathrm{~d} / 9$ dipasang di bagian atas dan bawah jaring sebagai penguat, sedangkan benang $210 \mathrm{~d} / 6$ dipasang di bagian tengah. Benang nilon adalah bahan yang baik untuk pembuatan pukat cincin. Hasil penelitian Slamet (1976) menunjukkan bahwa, bahan benang nilon memiliki kekuatan lebih baik serta mudah melepaskan air dibandingkan bahan kuralon, teteron maupun polyester. Sehingga benang nilon memiliki ketahanan dan kemudahan dalam penanganannya (tidak membutuhkan tenaga yang besar dalam pengoperasian). Kelemahan benang nilon adalah kecilnya nilai bobot jenis (specific gravity) yang menjadikan kecepatan tenggelamnya rendah. Namun hal ini dapat diimbangi dengan pemberian pemberat yang cukup untuk pukat cincin nilon. Menurut pemilik dan pembuat pukat cincin, penggunaan benang $210 \mathrm{~d} / 6$ adalah untuk menekan biaya pembuatan, oleh karena bahan jaring $210 \mathrm{~d} / 6$ lebih murah dibandingkan dengan $210 \mathrm{~d} / 9$, di samping itu pada saat pengoperasian jaring akan lebih ringan. Namun demikian pada kenyataannya, bobot atau ringannya jaring saat dioperasikan lebih ditentukan oleh bukaan mata jaring (lebih mengacu pada disain) dibandingkan diameter benang, karena bobot jaring dalam air hanya 10\% dari bobot di udara (Prado dan Dremiere, 1991).

Ukuran mata jaring (mesh size) yang digunakan adalah 0,75 inci (19,05 mm) untuk bagian kantong, dan 1,0 inci $(25,40 \mathrm{~mm})$ untuk bagian sayap dan di bawah kantong. Dari hasil pengukuran terhadap mata jaring yang digunakan sebagai contoh menunjukkan bahwa, ukuran mata dalam satu pis jaring berbeda-beda, dan umumnya lebih kecil dari ukuran yang tercantum dalam label. Dengan demikian pada saat akan membuat jaring pukat cincin diperlukan pemeriksaan ukuran mata jaring terlebih dahulu, agar konstruksi jaring sesuai dengan disain yang diinginkan. 
Panjang jaring pukat cincin ukuran sedang berkisar antara $250-400 \mathrm{~m}$. Jumlah jaring yang digunakan pada pukat cincin "sambung lima" adalah 48 pis, terdiri dari 2 pis bagian kantong, 46 pis bagian sayap dan di bawah kantong. Dengan menggunakan perhitungan massa jaring (1) diperoleh keseluruhan bobot bahan jaring (di udara) adalah $1048,6 \mathrm{~kg}$. Untuk pukat cincin "sambung enam" jumlah jaring yang digunakan adalah 67 pis, terdiri dari 3 pis bagian kantong dan 64 pis bagian sayap dan bawah kantong. Bobot bahan jaring (di udara) adalah $1465,4 \mathrm{~kg}$.

Pelampung yang digunakan pada pukat cincin ukuran sedang berbentuk oval dan berwarna putih, dari jenis S-3, S-4 dan Ds-4, dengan daya apung masing-masing 1,15 kgf, 0,75 kgf dan 1,00 kgf.

Bahan tali temali untuk ris dan srampat (selvedge) adalah polyetbilene (PE). Tali ris yang digunakan berdiameter 8,0 dan $10,0 \mathrm{~mm}$, tali kolor (purse line) dengan diameter $28,0 \mathrm{~mm}$. Ukuran mata untuk srampat antara 1,0-1,25 inci, dan dipasang di sekeliling pinggiran jaring, yang berfungsi sebagai penguat.

Pemberat yang digunakan dari bahan timah hitam $(\mathrm{Pb})$ dengan ukuran 200 g/buah. Sedangkan ring dibuat dari kuningan atau baja galvanis, dengan bobot per buah $800 \mathrm{~g}$.

Jenis dan ukuran bahan yang digunakan pada pukat cincin mempengaruhi resistensi dan bobot jaring dalam air dan menentukan kecepatan tenggelamnya. Iitaka (1965) yang mengungkapkan bahwa, kecepatan tenggelam pukat cincin dipengaruhi oleh nilai daya tenggelam keseluruhan material yang digunakan serta rasio antara diameter benang dan panjang bar. Secara praktikal, semakin besar nilai daya tenggelam, kecepatan tenggelam semakin tinggi. Pada pukat cincin proses tenggelam yang diharapkan selama dioperasikan adalah dalam keadaan terbentang sempurna. Oleh karena itu, kecepatan tenggelam ini dipengaruhi oleh resistensi dari setiap bagian badan jaring yang merupakan porsi terbesar konstruksi pukat cincin. Disinilah faktor rasio diameter benang (bahan jaring) dan panjang bar berperan.

Pukat cincin ukuran sedang tipe sambung lima dan sambung enam, menggunakan benang nomor $210 \mathrm{~d} / 12$ dan ukuran mata $19,1 \mathrm{~mm}$ untuk bagian kantong serta, $210 \mathrm{~d} / 9$ dan ukuran mata $25,4 \mathrm{~mm}$ untuk bagian bawah dan samping kantong. Pada Table 1 nampak bahwa, dengan dimensi bahan tersebut, nilai rasio antara diameter benang (D) dan panjang bar (L) pukat cincin ukuran sedang adalah 0,063 dan 0,039 , masing-masing untuk bagian kantong serta bawah dan samping kantong. Penggunaan jaring dengan bahan yang memiliki rasio $\mathrm{D} / \mathrm{L}$ kecil, memiliki kecepatan tenggelam relatif tinggi (Iitaka, 1965). Dengan nilai tersebut pukat cincin utara Jawa memiliki nilai resistensi yang memadai, mengingat pengoperasiannya untuk penangkapan ikan yang relatif dalam keadaan tenang (terkumpul di seputar rumpon dan atau di bawah cahaya lampu). 
Wijopriono dan Mahiswara

Table 1. The value of $D / L$ ratio of the medium size of purse seiner

\begin{tabular}{ccccc}
\hline No. & $\begin{array}{c}D \\
\mathrm{~mm}\end{array}$ & $\begin{array}{c}\boldsymbol{L} \\
\mathrm{mm}\end{array}$ & $D / L$ & $1 / \sqrt{ }(\mathrm{D} / \boldsymbol{L})$ \\
\hline $210 \mathrm{~d} / 12$ & 0,60 & 9,55 & 0,063 & 3,984 \\
$210 \mathrm{~d} / 9$ & 0,50 & 12,7 & 0,039 & 5,064 \\
$210 \mathrm{~d} / 6$ & 0,40 & 12,7 & 0,031 & 5,679 \\
\hline
\end{tabular}

Note: $\quad D$ : twine diameter $\quad L$ : length of bar

\section{Daya Apung dan Tenggelam}

Daya apung ditimbulkan oleh pelampung dan tali-temali, sedangkan daya tenggelam ditimbulkan oleh pemberat timah, cincin (ring) dan bahan jaring itu sendiri. Dengan menerapkan rumus perhitungan (II) diperoleh nilai daya apung dan tenggelam pukat cincin ukuran sedang yang dapat dilihat pada Table 2 dan Table 3.

Table 2. Bouyancy and sinking force of " 5 pieces borizontal" type of the medium size of purse seiner

\begin{tabular}{clccc}
\hline No. & Material & Number & $\begin{array}{c}\text { Bouyancy } \\
\text { (Kgf) }\end{array}$ & $\begin{array}{c}\text { Sinking force } \\
\text { (Kgf) }\end{array}$ \\
\hline 1. & Webbing & 48 & - & 104,9 \\
2. & Buoy & 790 & 772,5 & - \\
3. & Sinker & 1250 & - & 227,5 \\
4. & Ropes (Rope) & - & 15,9 & - \\
5. & Ring & 84 & - & 59,1 \\
\hline & Tot al & & 788,4 & 391,5 \\
\hline
\end{tabular}

Dari Table 2 dan Table 3 terlihat bahwa perbandingan antara daya apung dan tenggelam ( $S / F$ ratio) adalah sekitar 2 , atau daya apung adalah dua kali daya tenggelam. Perbandingan ini sesuai dengan nilai rasio daya apung dan tenggelam yang dikemukakan oleh Prado dan Dremiere (1991), bahwa dalam praktek nilai daya apung pelampung pada pukat cincin kira-kira sama dengan 1,5-2,5 jumlah pemberat yang dipasang. Daya apung yang lebih besar terdapat pada bagian kantong di mana pada bagian ini pelampung dipasang dengan jarak yang lebih rapat dari pada bagian lainnya. Hal ini dimaksudkan untuk mengimbangi gaya tenggelam yang ditimbulkan oleh bahan jaring pada bagian 
Table 3. Bouyancy and sinking force of "6 pieces horizontal" type of the medium size of purse seiner

\begin{tabular}{clccc}
\hline No. & Material & Number & $\begin{array}{c}\text { Bouyancy } \\
\text { (Kgf) }\end{array}$ & $\begin{array}{c}\text { Sinking force } \\
\text { (Kgf) }\end{array}$ \\
\hline 1. & Webbing & 67 & - & 146,5 \\
2. & Buoy & 1020 & 1020,0 & - \\
3. & Sinker & 1750 & - & 318,5 \\
4. & Ropes & - & 26,0 & - \\
5. & Ring & 86 & - & 75,7 \\
\hline & Total & & 1046,5 & 540,7 \\
\hline
\end{tabular}

ini yang memiliki jumlah pis lebih banyak, ditambah hasil tangkapan. Dalam banyak kasus, di mana hasil tangkapan berlimpah pada saat musim puncak, penambahan pelampung pada bagian kantong berupa jirigen dilakukan saat jaring telah dilingkarkan dan membentuk kantong. Hal ini disebabkan pelampung yang terpasang tidak dapat mengimbangi daya tenggelam yang ditimbulkan oleh hasil tangkapan.

\section{KESIMPULAN DAN SARAN}

\section{Kesimpulan}

(1) Pola potong pukat cincin ukuran sedang di perairan utara Jawa terdiri dua yaitu tipe selendang dan serong.

(2) Tinggi jaring pada konstruksi pukat cincin ukuran sedang adalah untuk menutupi kelemahan pengoperasian/penarikan dengan tenaga manusia.

(3) Nilai banging ratio pada konstruksinya berkisar antara 0,48-0,63, dengan nilai ini dapat diharapkan kecepatan tenggelam yang memadai saat dioperasikan.

(4) Pukat cincin ukuran sedang menggunakan bahan nilon dengan nomor benang antara $210 \mathrm{~d} / 6-210 \mathrm{~d} / 12$, material ini memiliki nilai kecepatan tenggelam yang rendah. Namun dengan nilai $S / F$ ratio 2 , dapat diharapkan penampilan jaring mendekati kecepatan tenggelam optimum saat dioperasikan.

\section{Saran}

Dilihat dari teknis perakitan, penanganan dan kekuatannya disarankan menggunakan konstruksi tipe selendang untuk pukat cincin ukuran sedang, khususnya pada kondisi perairan yang relatif dangkal. 


\section{DAFTAR PUSTAKA}

Ayodhyoa, A.U. 1981. Metode Penangkapan Ikan. Yayasan Dewi Sri, Bogor. 94 hal.

Iitaka. 1965. Studies on The Machanical Characters of the Purse Seine in Relation to Its Fishing Effeciency. Memoirs Faculty of Agriculture. Kinki University Vol 2, Tokyo.

Nurhakim, Subhat, Suherman Banon, M. Potier and T. Boely. 1987. Study on The Big Purse Seiners Fishery in The Java Sea II. Evalolution and Structure of The Javanese Purse Seiners Fleet. Jur. Pen. Perik. Laut No. 40. Balitkanlut, Jakarta. 65-76.

Yusuf, Nasocha. 1978. Perkembangan Purse Seine di Pemalang Khususnya, Umumnya di Perairan Utara Jawa (Makalah Simposium Modernisasi Perikanan Rakyat, Juni 1978. Lembaga Penelitian Perikanan Laut, Jakarta. 11 hal.

Potier, M., T.Boely and Subhat Nurhakim. 1990. Studi on The Big Purse Seiners Fishery in The Java Sea V. Estimation of The Effort. Jur. Pen. Perik. Laut No. 54. Balitkanlut, Jakarta. 79 - 95.

Potier, M. and B. Sadhotomo. 1995. Seines Fisheries in Indonesia in BIODYNEX, Editor Subhat Nurhakim and M. Potier. AARD Ministry of Agriculture, ORSTOM, EUROPEAN COMMUNITY, Jakarta. 49 -65.

Prado, J. and P.Y. Dremiere. 1991. Fisherman Work Book. FAO Rome, Italy. 174 p.

Sainsbury, John C. 1971. Commercials Fishing Methods. Fishing News Ltd., London. 119 p.

Slamet, Achmad. 1976. Suatu Studi Tentang Penggunaan Beberapa Jenis Benang Pada Jaring Purse Seine (Tesis). Fakultas Perikanan, IPB. 78 hal. 